\title{
From the Desk of Editor-in-Chief
}

Our beloved former editor-in-chief and former head, Department of Medicine, Enam Medical College \& Hospital, Savar, Dhaka Prof A. K. M. Rafique Uddin expired on October 18, 2013 (Inna lillahi wa inna ilaihi raziun). We are very much shocked at his sad demise. We do not know how to express our shock and pain. We pray to Allah for the eternal peace of the deceased in the hereafter life; we also express our heart-felt deep sympathy for the members of the bereaved family.

The present issue of the journal marks the $3^{\text {rd }}$ anniversary publication of Journal of Enam Medical College. We celebrate the anniversary issue to recommit ourselves each year to the idea that every issue of the journal has a chance to get ahead. It is the goal that motivates us every single day. We are always fighting for a better quality of the Journal of Enam Medical College. By the grace of The Almighty Allah so far our advancement is encouraging. We share this credit with all the teachers of Enam Medical College, all authors, reviewers and also office staff of the college. It is our pleasure not to forget the generous advice and cooperation of Chairman and Principal of Enam Medical College.

Journal of Enam Medical College is already recognised by Bangladesh Medical and Dental Council (BMDC) and indexed in nine indexing databases - national and international. During the last 6 (six) months period, the journal has been indexed in two databases - WHO Index Medicus for South-East Asia Region (IMSEAR) and Sjournals (Scientific Journals) Index. Inclusion of the journal in the IMSEAR database will pave the way for automatic indexation of Journal of Enam Medical College in WHO Global Index Medicus (GIM) managed by WHO Headquarters in Geneva. The process of indexing the journal in some other international databases is in progress and we will be continuing our effort to index the journal in many other famous international databases to further increase its visibility to the world scientific community. We have already submitted the journal to WHO Hinari. We have done the creative commons attribution 3.0 license (CC-BY). This license recommends for maximum dissemination and use of licensed materials within the boundaries of copyright law. We have also qualified the SPARC Europe Seal, allowing long-term archiving of contents, which means publishing in the journal more attractive to authors, better exposure as a high-quality journal based on state-of-the-art dissemination technologies and making metadata easily harvestable, thus increasing visibility of the papers and inclusion of details of journal articles in the database services of Open Access Initiative (OAI) harvesters.

The Journal of Enam Medical College will be published thrice a year from this calendar year - January, May and September. With this generous decision of the authority, we will now be able to accommodate more articles in the journal.

Constructive criticisms will always be continuing to be welcomed to improve the quality of the journal.

With best wishes.

\author{
Prof. Md. Aminul Haque Khan
}

Editor-in-Chief 